\title{
How Do You Watch Sports? Differences on Credibility, Viewing Satisfaction, Flow, and Re- viewing Intention between Public TV Stations and One - person Media via SNS
}

\author{
Chulhwan Choi' and Chul-Ho Bum² \\ ${ }^{1}$ Kyung Hee University, Department of Golf Industry, College of Physical Education, Yongin, Korea, ${ }^{2}$ Kyung Hee University, Department of Sports \\ Taekwondo, Graduate School of Physical Education, Yongin, Korea
}

\begin{abstract}
With advancements in the Internet and next-generation devices, one-person media sports broadcasts cause major changes in the sports broadcasting field, dominated by large TV broadcasting stations. The popularity of one-person media, especially among sports fans, and the presence of "influencers" with considerable impact are tremendous in the sports industry. In this context, this study assessed factors that drive media viewing based on (a) credibility, (b) viewing satisfaction, (c) flow, and (d) re-viewing intention. This study also analyzed recent sports media consumption patterns by comparing one-person media sports broadcasts with existing public TV broadcasts. The study results showed that mass appeal, flow, satisfaction with commentaries, satisfaction with video and sound, and satisfaction with the information provided significantly effect viewers' intent to re-view broadcasts in the future. Although existing TV broadcasts have more professionalism, trustworthiness, and mass appeal than one-person media, the latter provides more dynamism, satisfaction with video and sound, satisfaction with information provided, flow, and re-viewing intention. These study results indicate that rather than being a temporary trend, one-person media sports broadcasts obtained positive reactions in terms of re-viewing intention, based on high satisfaction and viewing flow of viewers, which are noteworthy in the sports media field.
\end{abstract}

Key words: broadcasting, one-person media, credibility, viewing satisfaction, flow, reviewing intention

\section{Introduction}

In the sports field, which has many ardent fans, the Internet has provided many benefits in different ways to those who develop and produce sports products and those who consume these products (Sutton, 2011). The sports broadcasting industry is known as among the largest industries in the sport field; its scale continues to grow (Mullin, Hardy, \& Sutton, 2014). The scale of sports broadcasting rights, or the right to bro- adcast sports games through media, is increasing by the day, along with the popularity of sports. Specifically, advertisement revenue, the merchandising industry, and other related businesses improved by pro sports broadcasting rights play an important role in the growth of the broadcasting rights industry (Horky, Clavio, \& Grimmer, in press).

Because the easiest way to consume sports is to watch sports broadcasts, it is necessary to study the consumption

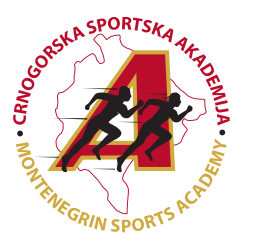

Correspondence:

C. H. Bum

Kyung Hee University, Department of Sports Taekwondo, Graduate School of Physical Education, Yongin, Korea

E-mail: bch2180@khu.ac.kr 
tendency of sports media viewers (Seo \& Green, 2008). Moreover, as the use of smartphones and other smart devices intensifies, viewers are no longer limited to watching sports through their TV at home; they can now watch live streaming of sports from different parts of the world in the palm of their hands, anytime and anywhere (Kang, 2015). This type of consumption was unimaginable for viewers in the past but has only become possible through the Internet and smart devices.

Another recent change in the sports broadcasting field is deeply connected to the growth of one-person media. Specifically, instead of a professional broadcaster, an individual creates and produces his/her own content through a personal blog or YouTube, and people across the world consume such content while chatting with the producer in real-time (Bloom, 2006). The spread and popularity of one-person media threatens public TV broadcasts; its ripple effect and influence have caused creators of one-person media broadcasts to be called "influencers" (Cho, 2011). The era of unilateral delivery of media products has long been over, and those that enable communication between producers and consumers have become the standard (Gohar, Mehmood, \& Sair, 2016).

In all sports broadcasts, including one-person media, the agent who broadcasts sports events and commentates on the game significantly impacts consumer choice (Kim, 2005). Moreover, because high ratings are closely related to profits from advertisements played during a sports broadcast, (a) a commentator's public confidence, (b) viewer satisfaction after watching a broadcast through media, (c) flow while watching a broadcast, and (d) a viewers' re-viewing intention are extremely important factors in analyzing sports media. These factors are required in an analysis given that in the new trend of one-person media format, regular individuals, instead of professionals commentating on sports broadcasts from public TV stations, are responsible for making commentaries.

First, credibility is defined as skills and reputation in providing a trustworthy, reasonable evidence (Berlo, Lemert, \& Mertz, 1969; Meyer, 1988). Since this reasonable evidence is delivered through a message, a credible message is closely related to the messenger of that message (Davis \& Krawczyk, 2010). Therefore, the commentator who delivers the intended message may be regarded as the most important factor in gaining public confidence or in the commentary of a sports broadcast. In the existing media, public confidence in a media broadcast is gained by recruiting professional commentators with a good reputation and who deliver high-quality broadcasts (Kim, 2005).

The concept of satisfaction is most important in not only the sports media industry but also all industries, because it is determined through the product that provides satisfaction or the quality of service; next to consumption, it is a factor that offers the most absolute impact on consumer behavior (Churchill \& Surprenant, 1982). Therefore, consumer satisfaction is often defined as an overall evaluation after the completion of consumption (Fornell, 1992). In examining an individual's satisfaction, many popular arguments say that initial expectation or prior experience must be compared against post-consumption experience (J. W. Kim, Magnusen, \& Y. K. Kim, 2014; Olson \& Dover, 1979). Tse and Wilton (1988) also supported the fact that consumer satisfaction/dissatisfaction is determined by disparity between initial expectation and perceived performance after consumption. Viewer satisfaction is also among the most important concepts in the sports broad- casting field and may be explained as the overall evaluation after one consumes the media content.

As the popularity of sports increases and with the creation of an environment where fans can watch sports games from across the world without restrictions, a sports broadcast must provide ardent fans with the experience of being at the actual game (Wenner \& Billings, 2017). Hence, the degree of flow through media inevitably becomes an important aspect of sports media (Park, 2011). The concept of flow refers to a state of extreme psychological entertainment or an individual's engagement in a certain task, and has characteristics, such as strong focus, loss of self, or a skewed sense of time (Csikszentmihalyi, 2000; Hamilton, Kaltcheva, \& Rohm, 2016). In other words, this means that fans become engaged in a sports broadcast, are unable to focus on other tasks, or do not feel that time is passing by because of their intense concentration (Park, 2011; Pynta et al., 2014). When this phenomenon is applied to the sports broadcasting field, intense flow has a positive impact on re-viewing intention.

Ultimately, re-viewing intention can be described as people's intent to watch something again when they have a positive experience with the content and quality of the media (Kang, 2016). Continuous viewing intention is an extremely important core factor in viewers within the fiercely competitive sports broadcasting field. Further, for one-person media sports broadcasting to secure more viewers and expand its range, it is important to analyze the degree of re-viewing intention among viewers. Meanwhile, sports broadcasting that uses the same media platform as TV must examine the re-viewing intention of viewers to assess the current situation.

\section{Research purpose and questions}

Therefore, the purpose of this study is to examine factors that drive media viewing based on (a) viewing satisfaction, (c) flow, and (d) re-viewing intention, and to analyze the consumption patterns of recent sports media by comparing one-person media sports broadcasts with existing public TV broadcasts. The following two research questions were designed based on these purposes.

RQ1. What factors on credibility, viewing satisfaction, and flow of sport broadcasting drive re-viewing intention?

RQ2. What are the differences in credibility, viewing satisfaction, flow, and re-viewing intention between one-person media sport broadcasting and public television sport broadcasting?

\section{Methods}

\section{Participants}

This study conducted a survey on individuals who watched soccer broadcasts from the 2018 FIFA World Cup Russia. This survey was conducted in the plaza in front of two different shopping complexes located in Seoul, South Korea, which have large floating populations; the survey targeted people who watched sports broadcasts through public TV or one-person media broadcasts on the Internet for a period of one month starting from when the World Cup began and ended, or from June 14 to July 16, 2018. All respondents voluntarily filled out the survey through a self-administration method.

\section{Measures}

The scale used in the study by Noe (2007) regarding the public confidence of soccer broadcast commentators and 
showing acceptable reliability (Cronbach's alpha level of 0.714 to 0.858 ) were revised and used accordingly. The four subfactors, namely, (a) expertise (4 items), (b) trustworthiness (4 items), (c) dynamism (3 items), and (d) mass appeal (3 items) had a total of 14 items measured on a 5-point Likert scale, ranging from 1 ("Strongly disagree") to 5 ("Strongly agree").

The scale used by Noe (2007) and Park (2011), who studied the psychology of consumers who watch soccer broadcasts, was revised and used accordingly. In more detail, there were three subfactors, namely, (a) satisfaction with the commentary ( $\alpha=0.821,4$ items), (b) satisfaction with video and sound $(\alpha=0.887,4$ items) and (c) satisfaction with information delivery $(\alpha=0.867,3$ items). The scale had a total of 11 items. Each question was measured on a 5-point Likert scale, ranging from 1 ("Strongly disagree") to 5 ("Strongly agree").

To measure the flow of viewers while watching a broadcast, the scale with an acceptable Cronbach's alpha result $(\alpha=0.836)$ in the study by Cho (2018), which analyzed motivation for using one-person media and flow, was revised to suit this study and used accordingly. This scale included 3 items. Each question was measured on a 5-point Likert scale, ranging from 1 ("Strongly disagree") to 5 ("Strongly agree").

Lastly, to measure re-viewing intention of viewers, the scale used in the study by Noe (2007) ( $\alpha=0.874)$ was revised and used accordingly. This scale included 3 items. Each question was measured on a 5-point Likert scale, ranging from 1
("Strongly disagree") to 5 ("Strongly agree").

\section{Data analysis}

To verify the factor structure of the research instruments, an Exploratory Factor Analysis (EFA) was performed, using Principal Component Analysis (PCA) with Varimax rotation. Additionally, to ensure internal consistency of the scores from the instruments, Cronbach's alphas were utilized. After these processes, a multiple regression analysis was conducted to verified cause-and-effect relationships of variables and a multivariate analysis of variance (MANOVA) was conducted to compare and analyze the differences in credibility, viewing satisfaction, flow, and reviewing intention of sports broadcasts between existing public television broadcasts and one-person media.

\section{Results}

\section{Descriptive statistics}

A total of 450 surveys were distributed, and 344 were returned (approximately $76.4 \%$ of response rate). After excluding 31 incomplete surveys, 309 surveys were finally utilized in this study. According to the viewing experiences in sports broadcasts, the current study categorized survey respondents into two groups: (a) public television broadcasts $(n=143,46.3 \%)$ and (b) one-person media $(n=166,53,7 \%)$. More detailed information for demographics was shown on Table 1.

Table 1. Frequency of Distributions for Demographic Variables

\begin{tabular}{ccc}
\hline Groups & $\begin{array}{c}\text { Group 1 } \\
\text { (Public television broadcasting) }\end{array}$ & $\begin{array}{c}\text { Group 2 } \\
\text { (One-person media) }\end{array}$ \\
\hline Media & $(\mathrm{n}=143,46.3 \%)$ & $(\mathrm{n}=166,53.7 \%)$ \\
Gender & Male $(\mathrm{n}=91,63.6 \%)$ & Male $(\mathrm{n}=96,57.8 \%)$ \\
& Female $(\mathrm{n}=52,36.4 \%)$ & Female $(\mathrm{n}=70,42.2 \%)$ \\
Age & 20s $(\mathrm{n}=48,33.6 \%)$ & $20 \mathrm{~s}(\mathrm{n}=74,44.6 \%)$ \\
& 30s $(\mathrm{n}=39,27.3 \%)$ & $30 \mathrm{~s}(\mathrm{n}=50,30.1 \%)$ \\
& $50 \mathrm{~s}(\mathrm{n}=34,23.8 \%)$ & $40 \mathrm{~s}(\mathrm{n}=25,15.1 \%)$ \\
& Hight school $(\mathrm{n}=47,32.9 \%)$ & Hight school $(\mathrm{n}=60,36.1 \%)$ \\
Education & Bachelor $(\mathrm{n}=86,60.1 \%)$ & Bachelor $(\mathrm{n}=89,53.6 \%)$ \\
& Graduate $(\mathrm{n}=10,7 \%)$ & Graduate $(\mathrm{n}=17,10.2 \%)$ \\
\hline
\end{tabular}

\section{Scale validity \& reliability}

The exploratory factor analysis using the PCA with Varimax of Credibility ( 4 factors, 14 items), Viewing satisfaction (3 factors, 11 items), Flow (3 items), and Reviewing intention (3 items) was conducted. The Kaiser Meyer-Olkin measure identified the sample adequacy for the analysis, $\mathrm{KMO}=.736$ (Field, 2009). Barlett's test of sphericity $\left(\chi^{2}=4226.733, \mathrm{df}=465, \mathrm{p}<.001\right)$ was statistically significant. Extracted 9 factors had eigenvalues greater than 1 and factor structure coefficients greater than .40.
The factors accounted for $69.79 \%$ of the total variance.

All Cronbach's alphas showed acceptable internal consistency for reliability based on the 70 cutoff (Nunnally \& Bernstein, 1994): (a) Credibility (Expertise, $\alpha=.749$; Trustworthiness, $\alpha=.733$; Dynamism, $\alpha=.801$; Mass appeal, $\alpha=.735$ ), (b) Viewing satisfaction (Commentary, $\alpha=.798$; Video and sound, $\alpha=.874$; Information delivery, $\alpha=.841$ ), (c) Flow ( $\alpha=.868$ ), (d) Reviewing intention $(\alpha=.887)$ (Table 2$)$.

Table 2. Factor Structure Matrix for Variables and Reliability

\begin{tabular}{lccccccccc}
\hline & $\mathbf{1}$ & $\mathbf{2}$ & $\mathbf{3}$ & $\mathbf{4}$ & $\mathbf{5}$ & $\mathbf{6}$ & $\mathbf{7}$ & $\mathbf{8}$ & $\mathbf{9}$ \\
\hline VS4 & .897 & & & & & & & & \\
VS1 & .831 & & & & & & & \\
VS3 & .828 & & & & & & & \\
VS2 & .816 & & & & & & & \\
CO4 & & .826 & & & & & & \\
CO1 & & .807 & & & & & & \\
\hline
\end{tabular}




\begin{tabular}{|c|c|c|c|c|c|c|c|c|c|}
\hline & 1 & 2 & 3 & 4 & 5 & 6 & 7 & 8 & 9 \\
\hline $\mathrm{CO} 3$ & & .804 & & & & & & & \\
\hline $\mathrm{CO} 2$ & & .696 & & & & & & & \\
\hline RI1 & & & .915 & & & & & & \\
\hline $\mathrm{RI} 2$ & & & .902 & & & & & & \\
\hline $\mathrm{RI3}$ & & & .825 & & & & & & \\
\hline FL1 & & & & .915 & & & & & \\
\hline FL3 & & & & .896 & & & & & \\
\hline FL2 & & & & .786 & & & & & \\
\hline EX4 & & & & & .819 & & & & \\
\hline EX1 & & & & & .750 & & & & \\
\hline EX2 & & & & & .712 & & & & \\
\hline EX3 & & & & & .680 & & & & \\
\hline IN3 & & & & & & .932 & & & \\
\hline IN1 & & & & & & .889 & & & \\
\hline IN2 & & & & & & .747 & & & \\
\hline TR4 & & & & & & & .769 & & \\
\hline TR1 & & & & & & & .763 & & \\
\hline TR2 & & & & & & & .726 & & \\
\hline TR3 & & & & & & & .660 & & \\
\hline DY1 & & & & & & & & .851 & \\
\hline DY3 & & & & & & & & .829 & \\
\hline DY2 & & & & & & & & .750 & \\
\hline MA3 & & & & & & & & & .886 \\
\hline MA1 & & & & & & & & & .832 \\
\hline MA2 & & & & & & & & & .660 \\
\hline E-VALUE & 4.863 & 3.098 & 2.707 & 2.143 & 2.029 & 1.985 & 1.734 & 1.644 & 1.433 \\
\hline VARIANCE (\%) & 15.69 & 9.99 & 8.73 & 6.91 & 6.54 & 6.40 & 5.60 & 5.30 & 4.62 \\
\hline$\alpha$ & .874 & .798 & .887 & .868 & .749 & .841 & .733 & .801 & .735 \\
\hline
\end{tabular}

Legend: $\mathrm{VS}=$ Satisfaction with video and sound, $\mathrm{CO}=$ Satisfaction with the commentary, Rl=Reviewing intention, $\mathrm{FL}=\mathrm{Flow}$, $\mathrm{EX}=$ Expertise, IN=Satisfaction with information delivery, $T R=$ Trustworthiness, $D Y=$ Dynamism, MA=Mass appeal.

\section{Multiple regression}

As results of the multiple regression, the regression model had an explanatory power with the following result: $F=5.646$, $p=.000, R^{2}=.131$ explaining $13.1 \%$ of the variance. More specifically, (a) Satisfaction with video and sound $(t=2.637$, $p=.009)$, (b) Satisfaction with information delivery $(t=2.584$, $p=.010)$, (c) Satisfaction with the commentary $(t=2.457$, $p=.015)$, (d) Flow $(t=2.403, p=.017)$, and (e) Mass appeal $(t=1.993, p=.047)$ factors in sports broadcasts increased reviewing intention of sport fans, whereas the rest of variables was not statistically significant (Table 3 ).

Table 3. Results of Multiple Regression

\begin{tabular}{ccccccc}
\hline & MODEL & B & SE & $\boldsymbol{\beta}$ & $\boldsymbol{t}$ & $\boldsymbol{p}$ \\
\hline \multirow{4}{*}{ CREDIBILITY } & & .546 & .578 & & .944 & .346 \\
& expertise & -.138 & .085 & -.095 & -1.633 & .104 \\
& trustworthiness & .099 & .091 & .062 & 1.089 & .277 \\
& dynamism & .029 & .071 & .025 & .413 & .680 \\
VIEWING & mass appeal & .140 & .070 & .110 & 1.993 & $.047^{*}$ \\
SATISFACTION & commentary & .183 & .075 & .135 & 2.457 & $.015^{*}$ \\
& video and sound & .170 & .064 & .146 & 2.637 & $.009^{* *}$ \\
FLOW & information delivery & .155 & .060 & .143 & 2.584 & $.010^{*}$ \\
\hline
\end{tabular}

Legend: ${ }^{*} p<0.05,{ }^{* *} p<0.01$. 
Multivariate Analysis of Variance (MANOVA)

The multivariate test indicated statistically significant differences based on the forms of media (Public television broadcasting and One-person media) [Wilks' lambda $=.455, F(9$, 204) $=39.758, p=0.00$, partial $\left.\eta^{2}=.545\right]$. Based on adjusted alpha level using Bonferroni correction $(P=0.05 / 9=.006)$, univariate tests for (a) Expertise, (b) Trustworthiness, (c) Dynamism, (d) Mass appeal, (e) Satisfaction with video and sound, (f) Satisfaction with information delivery, (g) Flow, and (g) Reviewing intention were statistically significant.

Table 4. Results of MANOVA: Differences in Credibility, Viewing Satisfaction, Flow, Reviewing Intention between Two Groups Based on Media

\begin{tabular}{cccccc}
\hline SOURCE & DV & $\mathbf{d f}$ & $\mathbf{F}$ & $\mathbf{p}$ & $\boldsymbol{\eta}^{\mathbf{2}}$ \\
\hline \multirow{3}{*}{ CREDIBILITY } & expertise & 1 & 95.421 & $.000^{* * * *}$ & .237 \\
& trustworthiness & 1 & 58.457 & $.000^{* * *}$ & .160 \\
& dynamism & 1 & 102.395 & $.000^{* * *}$ & .250 \\
VIEWING & mass appeal & 1 & 31.545 & $.000^{* * *}$ & .093 \\
SATISFACTION & commentary & 1 & 1.376 & .242 & .004 \\
& video and sound & 1 & 31.166 & $.000^{* * *}$ & .092 \\
FLOW & information delivery & 1 & 18.999 & $.000^{* * *}$ & .058 \\
REVIEWING INTENTION & 1 & 39.830 & $.000^{* * *}$ & .115 \\
\hline
\end{tabular}

Legend: *** $\mathrm{p}<0.001$.

However, the rest of the tests were not statistically significant: (a) Satisfaction with the commentary as shown in

Table 5. Mean Scores of Variances between Groups

\begin{tabular}{ccccccccccc}
\hline & $\mathbf{1}$ & $\mathbf{2}$ & $\mathbf{3}$ & $\mathbf{4}$ & $\mathbf{5}$ & $\mathbf{6}$ & $\mathbf{7}$ & $\mathbf{8}$ & $\mathbf{9}$ \\
\hline G1 & 3.205 & 3.184 & 2.433 & 3.175 & 2.816 & 2.573 & 2.646 & 2.492 & 2.527 \\
G2 & 2.434 & 2.611 & 3.398 & 2.622 & 2.929 & 3.170 & 3.155 & 3.231 & 3.076 \\
\hline
\end{tabular}

\section{Discussion}

\section{What factors drive re-viewing intention?}

The emergence of one-person sports broadcasts has gained popularity among rapidly changing viewers and is becoming a new way to watch and enjoy sports (Bloom, 2006; Cho, 2011). The results of this study showed that re-viewing intention is influenced by three factors related to viewing satisfaction (e.g., satisfaction with commentary, video and sound, and the information provided), mass appeal related to public confidence, and flow.

As mentioned above, this finding is consistent with research results arguing that the psychological factor of satisfaction has the strongest impact on the continuous behavior of consumers, as shown in previous studies (Kim et al., 2014; Park, 2011). Such results are not different from typical consumption behaviors of purchasing one out of countless products, which is expected in a situation where viewers must select and watch one media product from the many different channels that exist (Pedersen, Laucella, Kian, \& Geurin, 2017). Next, although mass appeal affects how viewers select media out of factors related to public confidence, it is implied that factors, such as expertise, trustworthiness, and dynamism, which used to be important factors in sports broadcasts by public TV stations (Hayes \& Carr, 2015; Spence, Lachlan, Edwards, \& Edwards, 2016), were unable to have a significant effect. Meaning, viewers focus on the depth of the commentator's relationship with viewers, rather than their skills, competence, or passion. Further, the recent popularity of one-person sports broadcasts, which enable a two-way communication through real-time chatting (Bloom, 2006; J.H. Kim \& B.H. Kim, 2017), means that viewers regard mass appeal with importance, which is related to the results of this study. Lastly, flow also had a significant effect on re-viewing intention, which is consistent with
Tables 4 and 5.

the results of previous studies that found satisfaction and flow to have a major impact on the psychology of viewers (Csikszentmihalyi, 1990; Park, 2011; Pynta et al., 2014). Considering how sports occur in real-time with unexpected results (Mullin et al., 2014), flow is inevitably an important factor.

\section{What are the differences between the two media?}

Through a comparative analysis, this study found that widely popular one-person media sports broadcasts communicate more with viewers than TV broadcasts do. As mentioned above, these results showed that the presence of influencers, which refer to individuals with a major impact on the Internet or social media, is not a temporary trend but, rather, may become another field of media that can draw the interest of viewers and satisfy their demands.

First, public TV sports broadcasts were rated higher in terms of factors related to public confidence (expertise, trustworthiness, and mass appeal), which is consistent with arguments that broadcast stations are making efforts to recruit competent and professional commentators (Spence et al., 2016; Harris, 2012; Hayes \& Carr, 2015). Meanwhile, because the influencers of one-person media provide more informal broadcasts than the commentators of public TV broadcasts do (Bloom, 2006; Cho, 2011; Lee, 2018; J.H. Kim \& B.H. Kim, 2017), the former are rated higher in terms of dynamism. However, sports broadcasts by existing broadcast stations obtained more positive reaction in terms of the overall evaluation related to public confidence.

Next, based on factors related to satisfaction, viewers were more satisfied with one-person media broadcasts in terms of satisfaction with video, sound, and information provided. This finding has significant implications. Since most one-person media broadcasts are created by an individual who is usually 
not an expert (Thompson, Martin, Gee, \& Geurin, 2017), the video, sound, and informative power of these broadcasts were not expected to compare with that of large broadcast stations, but the results proved differently. It shows that the quality of broadcasts that can be provided by individuals has improved through advancements in digital equipment using the Internet, and that these people can greatly improve their informative power by using the Internet that is full of information (Blank \& Lutz, 2018). Such results imply that the limitations of one-person media are slowly diminishing with the advancements in the Internet, and changes are to be anticipated in the future of sports media. In addition, there was no significant difference in satisfaction regarding commentaries.

Lastly, regarding flow and re-viewing intention, viewers were more responsive to sports broadcasts from one-person media than public TV broadcasts. The fact that one-person media provide more diverse content instead of being limited to sports broadcasts (Bloom, 2006; J.H. Kim \& B.H. Kim, 2017), it is expected to increase the flow of viewers more so than public TV broadcasts do. This may be seen as an advantage of the media that use the Internet. TV broadcasts needs to increase thei flow of their viewers by developing more diverse content. As mentioned in the results above, since one-person media is already highly rated in terms of satisfaction and flow, which are closely related to re-viewing intention (Csikszentmihalyi, 1990; Noe, 2007; Park, 2011), it is expected that this platform will be highly rated in terms of re-viewing intention. However, rather than seeing this as a simple outcome, it must be understood that this means there may be more consumers who will continue to watch one-person media broadcasts in the sports media market.

\section{Limitations and Future Study}

This study found significant results related to the population of one-person media sports broadcasts and the viewing patterns of sports fans. However, this study is not without its limitations. First, even though the survey respondents often watched both sports broadcasts through the TV and one-person media, they were forced to select one of the two media platforms. Therefore, future studies must analyze more types of viewers and add and analyze more diverse factors that were not included in this study.

Also, this study included everyone who watched broadcasts from countless influencers who offer sports broadcasts through one-person media. However, because TV sports broadcasts are only broadcasted by a few large stations with broadcasting rights vis countless individuals who can broadcast sports through one-person media, it is impossible to know the content of each individual's broadcast. Hence, future studies must filter out influencers with a more mass appeal and deduce more accurate research results based on analyses on influencers' broadcast content.

\section{Acknowledgements}

There are no acknowledgements.

\section{Conflict of Interest}

The authors declare that there are no conflicts of interest.

Received: 28 November 2018 | Accepted: 05 January 2019 | Published: 01 February 2019

\section{References}

Berlo, D.K., Lemert, J.B., \& Mertz, R.J. (1969). Dimensions for evaluating the acceptability of message sources. The Public Opinion Quarterly, 33(4), 563-576. doi: $10.1086 / 267745$

Blank, G., \& Lutz, C. (2018). Benefits and harms from Internet use: A differentiated analysis of Great Britain. New Media \& Society, 20(2), 618-640. doi:10.1177/1461444816667135

Bloom, J. (2006). Consumer Reviews and Recommendations Are Marketers' Most Powerful Tools. Retrieved 8/22, 2018, from http://adage.com/article/jonah-bloom/consumer-reviews-recomme ndations-marketers-powerful-tools/106092

Cho, S.W. (2011). Technologies in Big Data Era. Retrieved 9/5, 2018, from https://www.digieco.co.kr/KTFront/report/report_technical_report_ view.action?board_id=technical_report\&board_seq=5868\&gubun=aa\#

Cho, Y.H. (2018). Effects of interactivity of real-time Internet one-person broadcasting on parasocial interaction, social presence, and flow. Unpublished Master thesis. Seoul, Korea: Ewha Womans University.

Churchill, Jr.G.A., \& Surprenant, C. (1982). An investigation into the determinants of customer satisfaction. Journal of Marketing Research, 19(4), 491504. doi:10.2307/3151722

Csikszentmihalyi, M. (1990). Flow: The psychology of optimal experience. Cambridge, NY: University Press.

Csikszentmihalyi, M. (2000). Beyond boredom and anxiety: Experiencing flow in work and play. San Francisco, CA: Jossey-Bass.

Davis, D.C., \& Krawczyk, J. (2010). Female sportscasters' credibility: Has appearance taken precedence? Journal of Sports Media, 5(2), 1- 34. doi:10.1353/ jsm.2010.0004

Field, A. (2009). Discovering statistics using SPSS (3rd ed.). Thousand Oaks, CA: SAGE Publications.

Fornell, C. (1992). A national customer satisfaction barometer: The Swedish experience. Journal of Marketing, 56(1), 6-21. doi:10.2307/1252129

Gohar, N., Mehmood, B., \& Sair, S.A. (2016). A brand is no longer what we tell the customer it is-it is what customers tell each other it is: Validation from ahore, Pakistan. Science International, 28(3), 2757-2762.

Hamilton, M., Kaltcheva, V.D., \& Rohm, A.J. (2016). Social media and value creation: The role of interaction satisfaction and interaction immersion. Journal of Interactive Marketing, 36, 121-133. doi:10.1016/j.intmar.2016.07.001

Harris, K. (2012). Gender stereotypes, gender segregation, and credibility: Crossing the lines in sports media. The International Journal of Sport and Society, 3(2), 137-159.

Hayes, R.A., \& Carr, C.T. (2015). Does being social matter? Effects of enabled commenting on credibility and brand attitude in social media. Journal of Promotion Management, 21(3), 371-390. doi:10.1080/10496491.2015. 1039178

Horky, T., Clavio, G., \& Grimmer, C. (in press). Broadcasting the World Cup: A multinational comparative analysis broadcast quality in the 2014 World Cup. Soccer \& Society. doi:10.1080/14660970.2018.1448794

Kang, D.L. (2016). Influence of credibility in MC on flow, viewing satisfaction, and re-viewing intention in the English premier league. Unpublished Master thesis. Yongin, Korea: Kyung Hee University.

Kang, S. (2015). Exploring motivations, constraints, and perceptions toward sport consumers' smartphone usage. Unpublished Doctoral dissertation. Louisville, KY: University of Louisville.

Kim, J.W., Magnusen, M., \& Kim, Y.K. (2014). A critical review of theoretical and methodological issues in consumer satisfaction research and recommendations for future sport marketing scholarship. Journal of Sport Management, 28(3), 338-355. doi:10.1123/jsm.2013-0084

Kim, J.H \& Kim, B.H (2017). A study on the government PR using social media: Focused on the differences in perception between government PR practitioners and SNS professionals. The Korean Advertising and PR Practitioners Society, 10(1), 32-67.

Kim, S.K. (2005). A study on the recognition of public trust in MC for sports relay broadcasting. Unpublished Master thesis. Yongin, Korea: Kyung Hee University.

Lee, T.S. (2018). One-person Sport Media Is Moving into Mainstream Media. Retrieved 9/5, 2018, from http://news.mt.co.kr/mtview.php?no $=2018063015154222551$

Meyer, P. (1988). Defining and measuring credibility of newspapers: Developing an index. Journalism \& Mass Communication Quarterly, 65(3) 567-574. doi:10.1177/107769908806500301

Mullin, B.J., Hardy, S., \& Sutton, W. (2014) Sport marketing (4th ed.). Champaign, IL: Human Kinetics.

Noe, J.H. (2007). The effect of teenager's TV watching satisfaction and re-watching intention on public trust of sportscasters in the 2006 FIFA Germany World cup broadcasting. Unpublished Master thesis. Yongin, Korea: Kyung Hee University. 
Nunnally, J.C., \& Bernstein, I.H. (1994). Psychometric theory (3rd ed.). New York, NY: McGraw-Hill.

Olson, J.C., \& Dover, P.A. (1979). Disconfirmation of consumer expectations through product trial. Journal of Applied Psychology, 64(2), 179-189. doi:10.1037/0021-9010.64.2.179

Park, H.N. (2011). The study on viewer cognition and satisfaction level of south Africa world cup exclusive relay broadcasting. Unpublished Master thesis. Yongin, Korea: Kyung Hee University.

Pedersen, P.M., Laucella, P.C., Kian, E.D., \& Geurin, A.N. (2017). Strategic sport communication (2nd ed.). Champaign, IL: Human Kinetics.

Pynta, P., Seixas, S.A.S., Nield, G.E., Hier, J., Millward, E., \& Silberstein, R.B. (2014). The power of social television: Can social media build viewer engagement? A new approach to brain imaging of viewer immersion. Journal of Advertising Research, 54(1), 71. doi:10.2501/JAR-54-1-071-080

Seo, W.J., \& Green, B.C. (2008). Development of the motivation scale for sport online consumption. Journal of Sport Management, 22(1), 82-109. doi:10.1123/jsm.22.1.82
Spence, P.R., Lachlan, K.A., Edwards, A., \& Edwards, C. (2016). Tweeting fast matters, but only if I think about it: Information updates on social media. Communication Quarterly, 64(1), 55-71. doi:10.1080/0146337 3.2015.1100644

Sutton, W.A. (2011). Looking forward: A vision for sport marketing inquiry and scholarship. Sport Marketing Quarterly, 20(4), 242-248.

Thompson, A.J., Martin, A.J., Gee, S., \& Geurin, A.N. (2017). Managing social media marketing to develop event brand relationships: Perceived benefits, strategies and challenges. International Journal of Sport Management, 18(4), 488-515.

Tse, D.K., \& Wilton, P.C. (1988). Models of consumer satisfaction formation: An extension. Journal of Marketing Research, 25(2), 204-212. doi: $10.2307 / 3172652$

Wenner, L.A., \& Billings, A.C. (2017) Sport, media and mega-events. New York, NY: Routledge. 